\title{
As relações econômicas internacionais do governo Geisel (1974-1979) ${ }^{1}$
}

\author{
Brazil's international economic relations under Geisel (1974-1979)
}

RAPHAEL COUTINHO DA CUNHA* ROGÉRIO DE SOUZA FARIAS**

Rev. Bras. Polít. Int. 54 (2): 46-69 [2011]

\section{Introdução}

De meados da década de 1960 até o final da década de 1970, o Brasil ascendeu rapidamente na escala global de distribuição de poder econômico relativo, e, com isso, mudaram suas ambições e seu padrão de relacionamento com a economia mundial. O período no qual essas transformaçóes operaram de forma mais complexa foi durante a presidência de Ernesto Geisel (1974-1979). Esses processos ocorreram em um contexto de declínio relativo dos Estados Unidos e de distensão da Guerra Fria, os quais proporcionaram as condições para a adoção de uma política econômica externa cuja tônica, entre outras, era a diversificação de parcerias sob o signo da promoção do desenvolvimento econômico (Lessa 1995). A orientação da diplomacia econômica definiu-se, portanto, pela aproximação com outros parceiros, entre eles a América Latina, a África e o Leste Europeu (Lima e Moura 1982, 351-54). Ao mesmo tempo, o período caracteriza-se por um projeto de asserção da autonomia nacional voltado para a redução das vulnerabilidades do País frente às incertezas da economia internacional. Nesse sentido, é ilustrativa a afirmação do chanceler Azeredo da Silveira de que o Brasil deveria almejar a condição de potência para ter a capacidade de "prescindir de outras nações líderes naquilo que [fosse] essencial à consolidação de seu desenvolvimento". ${ }^{2}$

As relações econômicas internacionais não podem ser, no entanto, explicadas apenas por desígnios de ascensão, autonomia e diversificação. A atuação externa

\footnotetext{
1 Os autores agradecem ao Instituto de Relações Internacionais (IREL) da Universidade de Brasília (UnB) e ao Centro de Pesquisa e Documentação de História Contemporânea do Brasil (CPDOC) o apoio na participação na oficina Política externa e relaçôes internacionais do governo de Ernesto Geisel (1974-1979) e a Matias Spektor e André Villela pelos comentários e críticas a versōes anteriores do texto.

* Doutorando em Relaçōes Internacionais pela Ohio State University (raphaelcunha@gmail.com).

** Mestre e Doutorando em Relaçôes Internacionais pela UnB e Especialista em Políticas Públicas e Gestão Governamental do Ministério do Planejamento, Orçamento e Gestão (MPOG) (rofarias@gmail.com).

2 "Silveira: potência em 20 anos". O Estado de São Paulo, 18 de julho de 1976.
} 
brasileira durante a gestão Geisel encerra incoerências, conflitos e tensões que só podem ser compreendidos se levar-se em conta um conjunto de variáveis que interagem para determinar o padrão de comportamento do País na economia global. Neste artigo, trataremos daquelas que consideramos as principais tensões e incongruências da inserção econômica do período e proporemos um quadro analítico que ajude a explicar o comportamento do País e os resultados de suas açóes.

A primeira tensão diz respeito, de um lado, à busca da autonomia e da segurança econômica, para fazer frente às incertezas do ambiente econômico internacional e, de outro, à acentuação da dependência e da vulnerabilidade externa da economia brasileira no período. Se, por um lado, o Brasil adotou medidas que buscavam diversificar suas relações comerciais e atenuar sua dependência de insumos, bens de capital e petróleo importados, por outro, tomou decisóes que acabaram por aprofundar sua vulnerabilidade financeira e sua dependência do capital estrangeiro, bem como exacerbaram, em curto prazo, a necessidade de importação de petróleo e insumos importados. Para entender melhor essa questão, analisaremos os casos do endividamento externo brasileiro e da participação do capital estrangeiro no setor de exploração petrolífera.

A segunda questão diz respeito à mobilidade ascendente do Brasil em termos de poder econômico relativo no sistema internacional e às tensões e incongruências dela decorrentes no que tange ao processo de redefinição do interesse do País perante a economia política internacional. A hipótese discutida é que a melhora na posição relativa do País não se traduziu, direta e uniformemente, na expansão das ambições de sua política externa. O processo de mudança no comportamento depende não apenas da trajetória material, mas de como variáveis domésticas intermedeiam a relação entre alterações na posição relativa e comportamento externo (Lobell et al. 2009, 4-5; Rose 1998, 167; Schweller 2003, 317-18; Zakaria 1998, 35-37). Recorreremos aqui aos casos da expansão do crédito e investimento brasileiro direto no exterior; da atuação brasileira em relação aos cartéis de commodities; e do Sistema Econômico Latino-Americano (Sela).

Em terceiro lugar, observa-se que alguns resultados relativos à inserção econômica externa do País não decorrem necessariamente de políticas governamentais ou de projetos explícitos de política externa. Parte da literatura tende a atribuir a diversificação das relações econômicas no período a um projeto coerente que visava a proporcionar ao Brasil melhor posição nas barganhas com as grandes potências. No entanto, nem todos os resultados da diversificação podem ser entendidos nesses termos. Primeiro, porque algumas decisões relativas a questões internas afetaram negativamente a busca da diversificação da dependência. Segundo, porque houve dinâmicas econômicas exógenas que influenciaram o relacionamento do País com o exterior e que eram independentes das políticas governamentais adotadas. A esse respeito, serão analisados os casos da aproximação com a África negra e com o Oriente Médio. 
O que há de comum no tratamento das questôes e dos casos apresentados é o quadro analítico que propomos. Consideramos que para descrever e explicar a economia política da inserção externa brasileira do período é preciso atentar para dois grupos de variáveis. Primeiro, há as variáveis que estão no nível sistêmico, que dizem respeito à posição relativa do País no sistema econômico mundial e às oportunidades e restrições sistêmicas com que se depara o País em sua atuação externa. Essas variáveis, no entanto, não agem diretamente sobre o comportamento do País: as pressóes sistêmicas, assim como as oportunidades e as restrições do ambiente internacional, são filtradas e processadas por variáveis intervenientes no nível doméstico. As variáveis domésticas relevantes para nosso estudo são: as ideias e percepções dos tomadores de decisão; as disputas interburocráticas no interior do aparelho do Estado; a política doméstica; e as dinâmicas econômicas exógenas às políticas governamentais.

Acreditamos que esse marco analítico pode ser bem-sucedido na organização dos fluxos de causalidade que explicam a inserção econômica externa do País, podendo ser aplicado também a outros períodos. Ele ajuda a prevenir três problemas associados ao estudo da política externa brasileira. O primeiro é a explicação da inserção internacional do País somente pelo exame da retórica oficial e pelo voluntarismo dissociado das oportunidades e dos constrangimentos do sistema internacional. Nesses termos, o ponto de partida e o ponto de chegada das narrativas são comumente os epítetos concebidos pelos próprios decisores - "pragmatismo responsável", "diplomacia da prosperidade", "diplomacia do interesse nacional", etc. -, estruturados em uma concepção altista de agência, dado que se trabalha com o sistema internacional como categoria meramente contextual, e não como fator estruturante na análise. Além disso, esse tipo de análise tende a confundir as intenções declaradas dos atores com a ação propriamente dita. $\mathrm{O}$ segundo problema analítico opera em uma lógica inversa, pois transforma a ação dos Estados em mero epifenômeno das relaçôes de poder e dos fluxos econômicos internacionais, não havendo espaço para a agência do homem de Estado. Por fim, o terceiro problema que o marco analítico apresentado ajuda a dirimir é a noção de que não há, ou é mínima, a distância intertemporal entre ação dos agentes econômicos e estatais, de um lado, e suas consequências para a inserção econômica do País, de outro.

\section{Ajuste, autonomia e dependência}

Quando houve a troca de governo, em março de 1974, as condições estruturais que sustentaram o milagre econômico já haviam se esgotado. A economia aquecida pressionava as taxas de inflação, e o preço do barril do petróleo indicava que o Brasil, em longo prazo, teria que enfrentar problemas de reestruturação da economia (Fishlow 1986, 511). O enfrentamento era inevitável porque: (a) as reservas cambiais não poderiam cair abaixo de US\$ 2 bilhões, sob o risco de afetar a confiança dos investidores, um fator central na economia; (b) as importações não poderiam ser 
cortadas significativamente sem prejudicar o crescimento econômico - cerca de $75 \%$ das importações não energéticas eram relacionadas com investimentos; (c) o serviço da dívida externa brasileira já consumia 36\% das receitas das exportaçôes brasileiras; (d) o crescimento das exportações não conseguiria ter ritmo semelhante ao ritmo das importações em curto prazo, de maneira a diminuir a necessidade de financiamento externo destas; (e) a exploração de petróleo no País não seria suficiente para diminuir importações de combustível.

Frente ao choque externo advindo do aumento no preço do petróleo a partir de 1973 e ao elevado grau de endividamento externo do País à época, os decisores da política econômica se depararam com a necessidade de adoção de políticas de ajuste externo. As principais opções dos tomadores de decisão podiam ser resumidas a: (1) realizar um ajuste externo recessivo, com ênfase no realinhamento dos preços relativos (aumento dos preços domésticos de energia), desvalorização real para estimular as exportações e políticas fiscal e monetária restritivas para controlar a inflação; ou (2) implementar uma estratégia de ajuste "estrutural”, com investimentos na ampliação da capacidade produtiva doméstica de bens de capital e petróleo e da capacidade exportadora do País, fortemente ancorada em fontes de financiamento público e externo (Fishlow 1986, 519; Hermann 2005, 98-100). ${ }^{3}$

É à luz do diagnóstico nada otimista sobre o desempenho da economia, compartilhado por diversas figuras da burocracia econômica do País, que se deve analisar as motivações das primeiras ações do governo Geisel no campo econômico. Logo após sua posse, foi tomada a decisão de aumentar os preços dos derivados de petróleo e diminuir os controles de preços, o que indicava certa inclinação a adotar mecanismos de mercado para o ajuste da economia. Além disso, optou-se por uma restrição monetária e fiscal de forma a diminuir o crescimento da produção na economia já aquecida (Coes 1995, 18; Fishlow 1986, 514; Hermann 2005, 97; Macarani 2008, 8-10). ${ }^{4}$

Não houve, dessa maneira, a definição e implementação de uma estratégia de crescimento via endividamento no primeiro momento do governo. A adoção da via do ajuste pela entrada líquida de capital financeiro ocorreu de forma incremental, tendo se materializado no II Plano Nacional de Desenvolvimento (II PND), anunciado em meados de 1974. Tratava-se de um plano de investimentos públicos e privados dirigidos aos setores de infraestrutura, bens de produção, energia e exportação, que dependia, para sua viabilização, de fontes de financiamento público e externo (Hermann 2005, 100).

Como isso ocorreu em um governo altamente comprometido com o insulamento da economia brasileira? Dois fatores ajudam a explicar essa questão: as eleições legislativas de 1974 e a ampla disponibilidade de capital estrangeiro.

3 A discussão clássica sobre o dilema em torno dos dois tipos de respostas possíveis à crise - ajuste ou financiamento - encontra-se em Castro e Souza $(1985,28)$.

4 FMI. From: The Secretary. To: Members of the Executive Board. Brazil - staff report and proposed decision for the 1975 Article XIV consultation. SM/75/124. May 21, 1975. Confidential. 
Sobre o primeiro aspecto, convém considerar que Geisel estava profundamente comprometido com a manutenção das elevadas taxas de crescimento da economia como forma de dar estabilidade ao processo de abertura gradual do sistema político como a legitimidade do regime militar estava ancorada no crescimento econômico, qualquer abalo neste reverter-se-ia automaticamente em abalo naquela (Coes 1995, 18, 31 e 112; Fishlow 1986, 515; Gaspari 2003, 437-38; Gaspari 2004, 46). Quando o governo recebeu o resultado da derrota nas eleições parlamentares, no primeiro ano de gestão, não houve saída a não ser afastar-se de políticas que pudessem trazer recessão ao País (Macarani 2008, 10).

A grande oferta de recursos no mercado de capital internacional foi o segundo aspecto relevante, pois, sem isso, o Brasil não conseguiria desembolsar o volume de dólares adequado para o pagamento das importações. Foi somente no final de 1974 e início de 1975 que os mercados internacionais tiveram liquidez adequada para sustentar o endividamento brasileiro - a dívida externa do País, em 1974, saltaria de US $\$ 12,5$ bilhões para US $\$ 17,2$ bilhôes. $^{5}$

Inicialmente, as autoridades públicas eram descrentes da capacidade de o País captar externamente todos os recursos necessários para a sustentação da taxa de crescimento da economia. No final de 1974, Paulo Lira, presidente do Banco Central, mostrava-se cético quanto à possibilidade de o País conseguir somas significativas de recursos de origem árabe (petrodólares) em curto prazo. ${ }^{6} \mathrm{O}$ mesmo pode ser dito sobre Mário Henrique Simonsen, ministro da Fazenda. ${ }^{7}$ Outras autoridades do governo demonstravam equivalente descrença quando examinavam a capacidade do mercado de capitais europeus em sustentar as necessidades brasileiras. ${ }^{8}$ Mesmo assim, várias medidas foram tomadas para estimular a entrada de capital financeiro no País. Ainda no final do governo Médici, em fevereiro de 1974, tomou-se a decisão de suspender o requerimento mandatório de depósito de $40 \%$ do total equivalente em cruzeiros de moeda estrangeira proveniente de empréstimos internacionais. Em setembro de 1974, o prazo mínimo de maturidade dos empréstimos externos financeiros foi reduzido de 10 para 5 anos. ${ }^{9}$

Se as difíceis condições de financiamento externo facilitavam, inicialmente, a ação dos que buscavam o ajuste recessivo, devemos analisar como esse grupo atuou no início do governo Geisel, quando ainda não era nítida a capacidade de

5 FMI. From: The Secretary. To: Members of the Executive Board. Brazil - recent economic developments. SM/74/227. September 24, 1977. Confidential; Serviço Nacional de Informação. Apreciação Sumária no 9/74. EG pr 1974.03.00/1. Ver também o trabalho de Jeffry Frieden sobre as condições gerais de financiamento para a América Latina (Frieden 1991, 53-65).

6 NARA. Da embaixada americana em Brasília para o State Department. Economic tour d'horizon by Simonsen and Lira. 26 de novembro de 1974. Confidencial.

7 Sobre o ceticismo de Simonsen acerca da capacidade das instituiçôes financeiras de "reciclar" os recursos árabes, ver: Situação econômica mundial. 8 de outubro de 1974. EG pr 1974.03.28.

8 FMI. From: The Secretary. To: Members of the Executive Board. Brazil - staff report and proposed decision for the 1975 Article XIV consultation. SM/75/124. May 21, 1975. Confidential.

9 FMI. From: The Secretary. To: Members of the Executive Board. Brazil - recent trade and exchange measures. SM/79/63. February 27, 1979. Confidential. 
financiamento externo. No primeiro ano do governo, os resultados da economia brasileira eram muito preocupantes. A inflação esperada era de $20 \%$, tendo o ano fechado em 35\%; estimava-se um deficit comercial por volta de US\$ 1,5 bilhão, tendo ocorrido o triplo. Havia, dessa maneira, grandes incentivos para que houvesse propostas articuladas de ajuste da economia brasileira pela via contracionista. Elas, todavia, apresentaram-se tarde demais, além de não terem sido articuladas em um programa claro.

Uma dessas iniciativas veio de Marcos Vianna, presidente do Banco Nacional de Desenvolvimento Econômico (BNDE), que propôs uma "inversão de rumo" ao ministro do Planejamento, Reis Velloso, em março de 1976. A motivação da iniciativa estava nas crescentes críticas do setor privado à atuação do governo, o que demandava ajustes na política econômica como forma de manter o apoio desse setor. O centro do plano estava na contenção do poder estatal sobre a economia. Mesmo com esse propósito, Vianna concordava com a ação das empresas do Estado nos setores de petróleo, minério de ferro, aeronaves e vacinas. Na prática, a estratégia proposta por Vianna não mudava os fundamentos do modelo econômico e não tocava em problemas graves, como o financiamento externo e a inflação. Era uma rota alternativa que não trazia uma real inversão de rumos.

Outra iniciativa de ajuste da estratégia de crescimento brasileiro veio de Simonsen. Na área comercial, ele desprezava a estratégia de crescimento brasileiro calcada na proibição de importação de produtos capazes de concorrer com similares nacionais. Achava que o comércio internacional era uma avenida de mão dupla - se o Brasil tomasse medidas unilaterais de proteção, não haveria razão para se surpreender quando outros países o fizessem contra os produtos nacionais (Simonsen 1969, 177). Mas suas preocupações estavam voltadas para o domínio monetário e para a sustentabilidade da dívida externa. Seu maior alerta veio no texto $O$ problema da credibilidade externa brasileira, no qual alertava que a inflação, o deficit comercial, o excesso de despesas públicas e o crescimento da dívida externa iriam levar o País à bancarrota. Ele levava os sinais de perigo a Geisel, mas o comprometimento do presidente com a via da aceleração econômica não lhe permitia qualquer influência substantiva. ${ }^{10}$

Esse comprometimento era moldado pelas tendências da economia brasileira e por eventos conjunturais que davam periodicamente um sentido de otimismo sobre a capacidade brasileira de isolar-se da crise externa. Quanto ao primeiro ponto, observa-se que as exportações do País tinham crescido a uma taxa anual de $25 \%$ nos seis anos precedentes ao choque do petróleo, nível bem maior do que as taxas de juros cobradas no período (Macarani 2008, 8-9). Se essa tendência se mantivesse, e a dívida externa mantivesse ritmo de crescimento estável, a relação dívida/exportação declinaria com o tempo, tornando a dívida externa brasileira administrável. Assim, do ponto de vista econômico, a contratação de empréstimos

10 Ver O problema da credibilidade externa brasileira. Outubro de 1976. Secreto. EG pr 1974.03.28. Sobre a repercussão da ação de Simonsen no governo, ver (D’Araujo e Castro 2004, 189-90 e 293). 
internacionais com taxas de juros menores do que as expectativas de crescimento das exportações era argumento poderoso. Apesar de ter sido apresentado como equivocada uma década depois, houve poucas discussões sobre os riscos dessa estratégia no início da década de 1970. Além disso, se o primeiro choque do petróleo tivesse sido o único, ou se tivesse tido menor impacto, a estratégia de financiamento adotada pelo governo, em retrospecto, poderia ter sido aceitável (Coes 1995, 18-19, 112-13).

Sobre o otimismo alentado por eventos conjunturais, um bom exemplo foi a descoberta de petróleo na Bacia de Campos. A descoberta teve impacto nas predisposiçôes cognitivas tanto dos atores econômicos como dos oficiais do governo. A bolsa de valores teve alta e investidores revisaram para cima a capacidade de endividamento do Brasil, mesmo havendo fontes técnicas indicando que a diminuição significativa da dependência do petróleo estrangeiro ainda estava longe de ser alcançada. O clima de euforia se reforçava com estudos da própria Petrobras indicando que a produção nos novos campos poderia preencher $75 \%$ do consumo nacional dentro de 4 ou 5 anos. Como se sabe hoje, somente na década de 1990 essa meta foi alcançada. Mas, na época, a crença de que o aumento expressivo da autossuficiência estava próximo ajudou os decisores a conceber um quadro bem menos instável para a economia brasileira em médio prazo.

Em toda essa trajetória, o objetivo era ingressar na turbulência internacional diminuindo o nível de dependência externa. Mas, enquanto se buscava a independência no lado comercial da equação - com a ampliação do programa de substituição de importações e os investimentos em geração de energia e nas indústrias de bens de capital e intermediários -, no lado financeiro, a estratégia governamental de endividamento externo a aprofundava (Castro e Souza 1985, 41; Batista 1987, 69-77). A lógica do insulamento, que buscava aumentar a resistência da economia a choques externos, acabava alimentando a própria condição de vulnerabilidade do País - sobretudo em termos financeiros. Entre as crenças da elite militar e civil sobre os perigos da dependência externa e a necessidade política de manutenção das taxas de crescimento econômico, as premissas ideológicas foram colocadas de lado.

Não há exemplo mais claro desse processo de ruptura com o arcabouço de ideias nacionalistas do que o papel que o capital estrangeiro teve, no governo Geisel, em segmentos estratégicos da economia. Para Geisel, ideias liberais no campo econômico condenavam o País a uma posição subalterna - "as empresas estrangeiras podiam fazer o que quisessem, desde que fosse coisa que brasileiro não soubesse fazer" (Gaspari 2003, 294).

O difícil relacionamento entre insulamento e nacionalismo seria colocado à prova na busca do aumento da autossuficiência energética no segmento de petróleo e derivados. O dilema enfrentado pelos decisores era que, em curto prazo, a autossuficiência só poderia ser alcançada por meio de parcerias com empresas estrangeiras na exploração. A hipótese já era discutida desde a década 
de 1950, mas o nacionalismo era sempre vencedor nas batalhas decisórias. Quando o governo Kubitschek restabeleceu relações comerciais com a União Soviética e houve a possibilidade de troca de petróleo soviético por produtos brasileiros, por exemplo, Geisel foi contra e ajudou a dinamitar o projeto. Via na ideia sério perigo para o Brasil, pois isso criaria graves laços de dependência: os soviéticos poderiam vir a utilizar a situação para pressionar o Brasil ou simplesmente suspender os suprimentos. Geisel, desde essa época, achava que a importação de produtos essenciais criava problemas de dependência graves ao País, algo que foi aprofundado com a crise do petróleo (Gaspari 2003, 63; D’Araujo e Castro 1997, 247).

No governo Médici, alguns ministros da área econômica desejavam franquear a empresas estrangeiras a exploração de petróleo nacional por intermédio de contratos de risco. Geisel novamente foi contrário à ideia; para ele, "não tinha sentido o 'Brasil Grande' chamar estrangeiros para fazer esse serviço" (Gaspari 2003, 258). Agora, confrontados com a crise do petróleo, o tema voltava à pauta. Geisel relata da seguinte forma a questão:

Quando a situação do nosso suprimento foi ficando mais grave devido à exagerada multiplicação dos preços, e vendo que a resposta que a Petrobrás vinha obtendo não era muito promissora a curto prazo, pelo menos em nível que correspondesse às necessidades do Brasil, Veloso e outros fizeram a sugestão de abrir o Brasil aos contratos de risco. Eu relutei muito. Não era muito favorável, mas acabei concordando e fui à televisão anunciar a decisão de autorizar esse tipo de contrato. (...) Relutei em aceitar [os contratos de risco] porque eu era favorável ao monopólio, achava que a Petrobrás devia tomar conta de todo o problema do petróleo. Tive que aceitar, contudo, em face da emergência que o país atravessava. (D’Araujo e Castro 1997, 307-308). ${ }^{11}$

Percebe-se, a partir da declaração de Geisel, que ele tomou posições contrárias às suas crenças sobre a participação do capital estrangeiro na exploração do setor estratégico de petróleo. A razão dessa aparente contradição é o fato de a debilidade engendrada pela crise econômica externa ter demandado um aprofundamento da busca pela autossuficiência que não poderia ser conseguida em curto prazo sem a ajuda externa. $\mathrm{O}$ incessante desejo de que o Brasil seguisse como uma ilha de prosperidade em meio à turbulência mundial traduzia-se, no caso, em fortalecimento dos laços com as grandes corporaçôes internacionais, a despeito do profundo nacionalismo do governo.

Da análise conclui-se que não foi inevitável a implementação de um projeto de crescimento pela via do endividamento. No início do governo, tentou-se um tímido ajuste e, posteriormente, vários atores governamentais defenderam, sem

11 Assim, Roberto Campos confidenciava para o cônsul americano no Rio de Janeiro, em julho de 1974, que Geisel afirmou, em conversa com Campos, ser favorável, àquela altura, à participação de empresas estrangeiras na exploração de petróleo no Brasil. NARA. De John Crimmins (Brasília) para o State Department. Brazil's oil exploration policy. 18 de julho de 1974. Confidencial. 
sucesso, esse rumo. A liquidez do sistema financeiro internacional (Devlin 1989, 123-39), por um lado, e as crenças das lideranças políticas de que era necessária a continuidade do crescimento econômico para sustentar o regime, por outro, deram os meios e os fins das ações governamentais. Estas, no entanto, não foram condizentes com as premissas de autossuficiência dessa elite política - o que traduz relevante contradição na política econômica externa do período.

Em suma, as decisões que resultaram no aprofundamento da dependência externa no período, em termos de endividamento e de participação de empresas estrangeiras na economia brasileira, foram fortemente condicionadas por choques externos (preço do petróleo e liquidez financeira) e constrangimentos políticos internos (necessidade de sustentação do regime). Essas variáveis constituíram clara limitação aos ímpetos de autonomia frente à economia mundial.

\section{Mobilidade, restrições e política econômica externa}

O governo Geisel coincidiu com o fim de um período de exuberante crescimento econômico. Havia, então, a crença "de que o país podia, efetivamente, transcender suas circunstâncias históricas, melhorar seu posicionamento relativo na estrutura internacional de poder" (Spektor 2004, 196). Inicialmente, esta seção analisará como o Brasil atuou, em certas ocasiões, de forma ágil na reestruturação de sua ação no sistema internacional face às alterações em sua posição relativa. Para isso, examinaremos a expansão do crédito além das fronteiras e a posição do País na formação de cartéis de commodities (minério de ferro). Em seguida, analisaremos casos em que não foi realizada uma reavaliação da atuação do País diante de uma nova realidade. $\mathrm{O}$ fracasso na implementação da correção de interesses será ilustrado por dois casos: a projeção econômica brasileira no Equador e a atuação do País dentro do bloco dos países em desenvolvimento nas iniciativas econômicas multilaterais do período. Em cada caso, serão explicitadas as variáveis que intermediaram a transmissão das pressōes de nível sistêmico para a política econômica externa brasileira.

\section{Investimento e crédito externo brasileiro}

Em algumas ocasiōes durante a gestão Geisel, os atores governamentais perceberam os sinais do sistema internacional e conseguiram não só mudar a concepção de interesse do País como implementar mudanças nas políticas de acordo com essa nova percepção. Um primeiro aspecto relevante foi a projeção externa brasileira por meio de empréstimos e financiamentos de longo prazo e investimento direto no exterior (ver gráficos a seguir). $\mathrm{O}$ aumento da capacidade econômica brasileira foi acompanhado de correções nos rumos da projeção econômica externa do País. Em certas áreas geográficas, esse era um processo que já vinha 
do início da década de 1970 (Schneider 1974, 15). Com o governo Geisel, esses ajustes se tornaram mais sintomáticos, principalmente no âmbito da América do Sul. Havia, naquele momento, a percepção de que o Brasil deveria ajustar de vez seu comportamento externo, que não era mais compatível com atitudes tímidas. O desenvolvimento econômico doméstico demandava a ruptura dos grilhões que prendiam o País em uma condição de timidez estrutural na sua inserção econômica internacional. Era necessário desembolsar recursos para projetar interesses. ${ }^{12}$

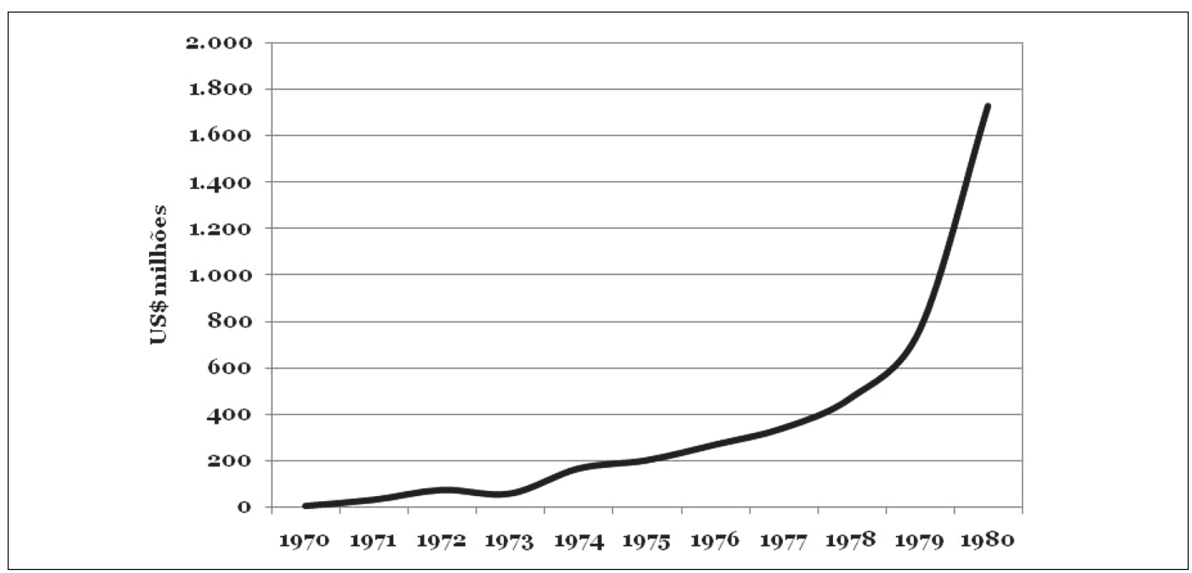

Gráfico 1. Empréstimos e financiamentos de longo prazo concedidos pelo Brasil (desembolso), 1970-1980.

Fonte: Banco Central do Brasil.

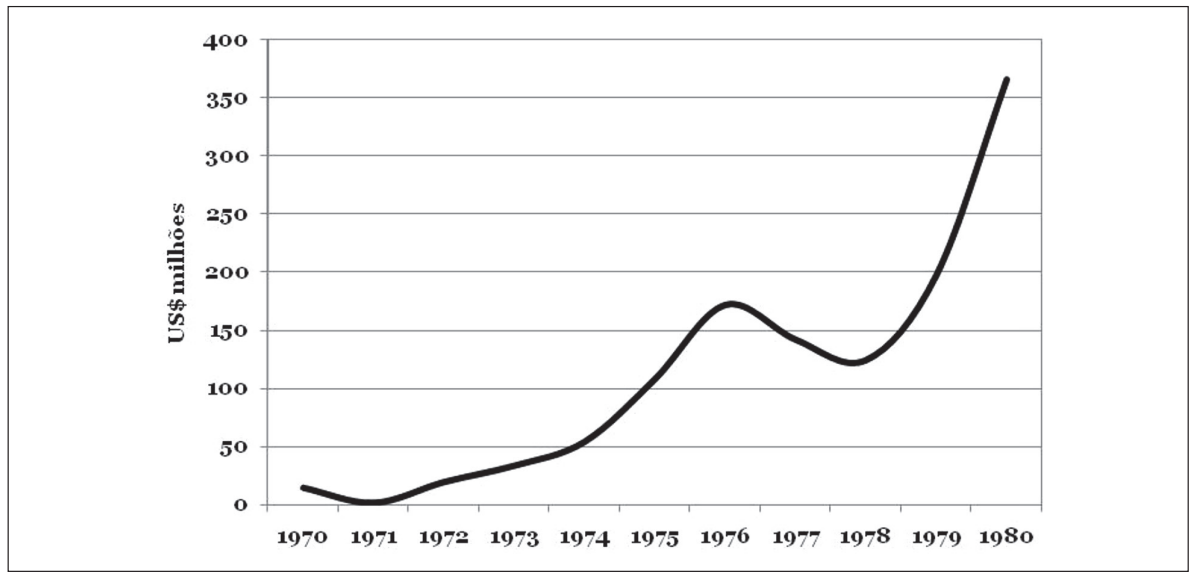

Gráfico 2. Investimento brasileiro direto no exterior (fluxo líquido), 1970-1980. Fonte: Banco Central do Brasil.

12 A instância mais representativa desse processo foi o abandono da "cordialidade oficial" nas relaçôes bilaterais com a Argentina, apresentado em Spektor (2002, 94-95). 
Em termos agregados, nos Gráficos 1 e 2 é possível ver a projeção externa do País em termos financeiros: houve sensível aumento do investimento externo brasileiro e de empréstimos, principalmente por parte de empresas estatais e construtoras privadas. Como apontam Iglesias e Veiga (2002), essa primeira fase do investimento de empresas brasileiras no exterior se concentrou na Petrobras, em instituições financeiras e em empresas de construção. Como indicadores sobre a atuação financeira brasileira são difíceis de serem desagregados, pode-se trabalhar com exemplos específicos encontrados. Um deles foi a criação do Banco Interamericano de Poupança e Empréstimo (Biape)..$^{13}$ Tratava-se de uma sociedade anônima criada no âmbito americano para fomentar empréstimos habitacionais. $\mathrm{Na}$ divisão acionária, o Brasil optou por ter a maior participação, conjuntamente com a Venezuela (cada um com 35\%). Não é possível saber o impacto da instituição, mas o ativismo, em termos relativos na distribuição das quotas, é enorme - e, curiosamente, semelhante com o padrão existente na proposta de criação do Banco do Sul, nos anos 2000. ${ }^{14}$

Muitas vezes, no entanto, a pressão do sistema internacional e a retórica oficial chocam-se com idiossincrasias dos tomadores de decisão. Assim, quando se fala no aumento do arco de projeção brasileiro na América do Sul, deve-se considerar que isso não ocorreu sempre. Houve casos em que, mesmo havendo recursos, harmonia da iniciativa com as premissas ideológicas do regime, empreendedores bem posicionados no aparelho estatal e interesse dos países vizinhos, o Brasil não conseguiu lançar-se com desenvoltura. É o caso, por exemplo, da expansão brasileira no Equador. O país, que não tem fronteira com o Brasil, tinha importância marginal para a inserção externa brasileira na América do Sul. No início da década de 1970, no entanto, observou-se ação crescente de empresários e militares brasileiros no país.

Os militares interessavam-se pela integração física da região amazônica. ${ }^{15}$ O projeto central era a chamada Via Interoceânica e seu plano inicial era de 1960 - uma via de transporte que saía da cidade portuária de San Lorenzo, passava por Quito e chegava a Manaus, totalizando $3.735 \mathrm{~km}$, que só começou a sair do papel no fim do governo Médici, por falta de recursos para a iniciativa até então. No início da gestão de Geisel, a construtora Camargo Corrêa preparava-se para assumir a construção do trecho rodoviário equatoriano, a Carteira de Comércio Exterior do Banco do Brasil (Cacex) e o Banco do Brasil se articulavam para aportar os recursos, e o Itamaraty cuidava dos canais de interação políticos. Seria, depois de concluído, o principal sinal tangível da presença brasileira no Equador.

$13 \mathrm{O}$ capital total do Biape pode ser considerado pouco volumoso, o que coloca em questão a representatividade do caso escolhido. Porém, trata-se de um dos únicos casos documentados em que se pode comparar a ação do Brasil com a de outros países da região.

14 Reunião Preparatória para a criação do Biape. Av. no 143. Em 25 de fevereiro de 1975. De Golbery do Couto e Silva para Antonio Francisco Azeredo da Silveira. AAS. MRE/AI 1974.06.07

15 NARA. Da embaixada americana em Quito para o State Department. The Brazilian influence in Ecuador. 30 de abril de 1975 . 
Quando houve a necessidade de aprovação presidencial para o início das obras, Geisel determinou o engavetamento do projeto. A justificativa inicial era uma questão de ordem prática: não havia razão para financiar a obra se o Equador, exportador de petróleo, tinha condições de arcar com os custos. Segundo, e mais importante - o presidente, considerando sua experiência pessoal com os equatorianos durante sua gestão na Petrobras, afirmava não ter tido "qualquer manifestação efetiva de colaboração" com o país, sem contar que "um Oficial do Exército brasileiro não [havia sido] aceito para cursar a Escola Superior de Guerra de Quito". ${ }^{16}$ Mesmo tendo todas as condições possíveis no plano doméstico e internacional, mesmo sendo o projeto harmônico com as pressões de expansão e mobilidade do sistema internacional, o homem de Estado obstou a projeção maior do Brasil no Equador. Somente em 1995 os dois países voltaram a discutir seriamente a construção da Via Interoceânica. ${ }^{17}$

\section{Formação de cartéis}

Já no plano das relações multilaterais do País, uma referência de ajuste previsível entre o comportamento esperado e o efetivamente observável na política econômica externa foi a questão do cartel de minério de ferro. Fica explícito, no caso, que as lideranças domésticas brasileiras percebiam como limitadas as vantagens potenciais que poderiam advir com a organização dos mercados de produtos primários, em um período que marcou o maior sucesso de cartelização do século 20. Dessa forma, apesar das iniciativas de diversos países em desenvolvimento para estender o sucesso do caso do petróleo a outros produtos, o Brasil teve posição distinta no caso do minério de ferro, demonstrando não ser um alinhado decidido do Terceiro Mundo no plano multilateral, como indicavam as primeiras pesquisas sobre o período (Lima e Moura 1982, 356). ${ }^{18}$

Até 1973, o Brasil buscava estabelecer arranjo com outros produtores de minério de ferro - principalmente Canadá, Austrália e África do Sul - para aumentar o preço do produto. ${ }^{19}$ Contudo, em 1974, a posição do Brasil já era outra: não havia mais desejo em participar de um cartel do ferro. A justificativa apresentada era que, primeiro, ao contrário da Organização de Países Exportadores de Petróleo (Opep), havia um número excessivo de países mineradores de ferro,

16 Aviso no 130 de Golbery do Couto e Silva para Antônio Francisco Azeredo da Silveira. Em 21 de fevereiro de 1975. AAS MRE/RB 1974.03.19. Pasta I.

17 Protocolo de entendimentos entre os governos da República Federativa do Brasil e da República do Equador sobre a realização de projeto da Via Interoceânica. Brasília, 5 de setembro de 1995. [http://ww.mre.gov.br].

18 Em sua tese de doutorado, a autora muda substantivamente o argumento (Lima 1986, 413).

19 NARA. Do State Department para a embaixada americana em Brasília. Iron ore - alleged attempt by Brazil to establish world marketing arrangements. 17 de julho de 1973. NARA. Do consulado americano em Perth para o State Department. Iron ore: alleged attempt by Brazil to establish world marketing arrangements. 13 de agosto de 1973 . 
tornando difícil a criação de um cartel - a maior disponibilidade dos depósitos de minério ao redor do mundo dificultava a necessária coordenação. ${ }^{20}$ Segundo, o Brasil estava investindo pesadamente no aumento das exportações do produto. Já em 1973, tinha-se a expectativa de que, com o aumento da produção, o Brasil seria o maior exportador mundial de minério de ferro em $1980 .{ }^{21}$ De fato, os dados disponíveis indicam que a participação brasileira na produção mundial de minério de ferro dobrou entre 1972 e 1980 , passando de $6 \%$ para $12 \%$ no período. A participação nas exportações mundiais do produto cresceu em ritmo ainda maior, tendo aumentado de cerca de $8 \%$ em 1972 para $22 \%$ em 1980 - um ritmo de crescimento elevado sob qualquer ponto de vista. ${ }^{22}$

A cartelização do setor, no entanto, ao estabelecer quotas de exportação, impediria o crescimento das exportaçóes brasileiras. Considerando que esse movimento de expansão era superior ao dos concorrentes, o País abdicaria de aumentar sua participação no mercado mundial de minério de ferro se houvesse fixação de quotas nos níveis do início da década de 1970. Essa percepção fica explícita em outubro de 1975, quando Shigeaki Ueki, ministro das Minas e Energia do Brasil, envia mensagem ao ministro do comércio da Índia, D. P. Chattopadhyaya, na qual declara ser "prematuro" um esquema de valorização do minério de ferro. A decisão brasileira, para o ministro brasileiro, estava calcada no autointeresse do País: buscava-se a liderança mundial na produção do minério e achava-se que a entrada em um grupo no qual ocorreria o congelamento do crescimento da produção por um sistema de quotas de exportação prejudicaria esse objetivo. Não havia uma objeção filosófica a esquemas de organização de produtores; a iniciativa apenas não atendia aos interesses brasileiros de longo prazo nessa instância específica. $\mathrm{O}$ interesse decorrente de uma percepção de ascendência futura na ocupação do mercado de minério de ferro traduziu-se de forma direta na política econômica externa do País.

A crítica brasileira à cartelização do setor trouxe problemas. Para um diplomata americano, a decisão do governo brasileiro de abertamente obstar a criação do cartel do ferro acabou reduzindo a credibilidade do governo junto a outros atores do mundo em desenvolvimento. ${ }^{23}$ Foi o custo que se decidiu pagar para se garantir a expansão e mobilidade do País.

Todavia, nem sempre o País decidiu arcar com os custos do isolamento. Havia, entre decisores brasileiros, a percepção de que o desenvolvimento do País

20 NARA. Do consulado americano no Rio de Janeiro para o State Department. Brazilian participation in iron ore club. 15 de outubro de 1974 .

21 NARA. De John Crimmins (Brasília) para o State Department. Organization of iron ore exporting nations. 8 de agosto de 1974.

22 Bureau of Mines. Minerals yearbook area reports: international. Washington: U.S. Bureau of Mines. Números de 1972 a 1980; Banco Mundial (WITS); GATT. Consultation Under Article XVIII:12(b) with Brazil: Basic Document for the Consultation. BOP/209. 1981.

23 NARA. De John Crimmins (Brasília) para o State Department. 30 $0^{\text {th }}$ UNGA - Agenda item 123 (Brazilian trade agreement proposal). 3 de novembro de 1975 . Confidencial. 
faria com que ele compartilhasse certos interesses com os países desenvolvidos. ${ }^{24}$ Mas esse rápido crescimento era visto com desconfiança por alguns países em desenvolvimento. ${ }^{25}$ Aqueles mais radicais viam com suspeição a nova retórica brasileira nos fóruns multilaterais econômicos. $\mathrm{Na}$ abertura da Rodada Tóquio do Acordo Geral de Tarifas e Comércio (Gatt), por exemplo, o Brasil adotou uma posição moderada, distante do radicalismo de outros países latino-americanos. ${ }^{26}$ Carlos Hugueiras, chefe da divisão de política comercial da chancelaria peruana, confidenciava para diplomatas americanos que o Brasil, em muitos sentidos, era um país desenvolvido que tinha visão de mundo distinta da perspectiva defendida pela maioria dos países da região. ${ }^{27}$

Porém, o desejo de evitar o isolamento constrangeu o governo brasileiro a não externar as suas reservas às iniciativas radicais do mundo não alinhado. Contribuía para isso a percepção de que o País tinha escassa influência para exercer uma pressão moderadora sobre esse grupo. Portanto, apesar de chegar, em alguns casos, a conclusões precisas quanto às reais possibilidades de sucesso das iniciativas terceiro-mundistas, o Brasil optou por manter atitude discreta na propagação de ideias contrárias à articulação desses arranjos.

Em âmbito reservado, atores governamentais brasileiros pronunciavam-se contrariamente a essas iniciativas, principalmente as concentradas na América Latina. Um desses exemplos foi a atuação brasileira na construção do Sela. A ideia, lançada por Venezuela e México, era, sobretudo, voltada para regular o comércio e as finanças internacionais com base em parâmetros semelhantes aos da Nova Ordem Econômica Internacional proposta na Assembleia Geral das Naçōes Unidas. Severo Gomes, ministro da Indústria e Comércio, em fevereiro de 1975, como resposta à iniciativa do Sela, confidenciava que a formação de cartéis internacionais para a defesa dos preços de matérias-primas não era uma solução desejável para os países em desenvolvimento. O Itamaraty também tinha restrições à proposta. ${ }^{28}$ De acordo com Luiz Felipe Lampreia, diplomata brasileiro, o Brasil era contra a iniciativa, mas, se a criação da instituição fosse inevitável, o País teria de participar e exercer uma influência voltada para políticas razoáveis e efetivas. ${ }^{29}$ Foi o que de fato ocorreu. Mesmo havendo no governo vozes contrárias à atuação brasileira nos

24 NARA. De John Crimmins (Brasília) para o State Department. Non-aligned activities in international organizations. 2 de julho de 1974. Confidencial.

25 NARA. De John Crimmins (Brasília) para o State Department. OPEC price increase. 22 de dezembro de 1973. Confidencial.

26 NARA. Da missão americana em Genebra para o State Department. GATT Committee on trade and development, June $12-15$ and 19. 21 de junho de 1973

27 NARA. Da embaixada americana no Peru para o State Department. Peru and MTN: GATT Tokyo Ministerial, OAS/SCCN meeting, and CECLA. 10 de setembro de 1973.

28 “(...) os estudos preliminares efetuados pelo Itamaraty previamente à recente Conferência do Panamá sobre a criação do SELA suscitaram dúvidas quanto aos objetivos e ao funcionamento do Sistema." Av. no 787 de Golbery do Couto e Silva para Antonio Francisco Azeredo da Silveira. Em 3 de setembro de 1975. AAS. MRE/ AI 1974.06.07.

29 NARA. De John Crimmins (Brasília) para o State Department. Gob reserve don SELA. 6 de março de 1975. 
arranjos do Sela, o Itamaraty decidiu não externar as reservas do País no plano multilateral e, ainda, participar do arranjo. ${ }^{30}$

Os casos discutidos nesta seção mostram que, frente a um mesmo conjunto de constrangimentos estruturais - decorrentes do incremento na posição relativa do Brasil na economia internacional desde a década de 1960, em termos de sua participação do Produto Interno Bruto (PIB) mundial -, o País respondeu de forma diversa a diferentes desafios. Se, em determinadas ocasiōes, os tomadores de decisão lograram reavaliar o interesse brasileiro, imprimindo mudanças no curso de ação tradicional do País (como nos casos do investimento e crédito brasileiro no exterior e do cartel da mineração), em outros momentos, o País se ateve a trajetórias passadas, não implementando mudanças esperadas, ainda que graduais, por conta de sua ascensão relativa (como, por exemplo, no caso do Sela).

Variáveis sistêmicas, portanto, não são suficientes para explicar as variações observadas no comportamento externo brasileiro no conjunto de casos apresentados. Para entender as variações na política externa econômica, teve-se que lançar mão de variáveis domésticas intervenientes que interferiram na forma como os sinais do ambiente internacional foram filtrados e transformados em ação.

\section{Desvios do pragmatismo responsável}

No governo Geisel, em diversas instâncias, a inserção econômica externa do País não decorreu diretamente de políticas governamentais ou da retórica da política econômica externa associada ao período, apesar de alguns resultados serem convergentes com essas variáveis. Há, em certos casos, disfunção causal entre retórica, ação e resultados - indicando a importância de se analisar variáveis em outros níveis explicativos e o aspecto intertemporal da ação governamental. Serão analisadas aqui as decisóes políticas do governo com relação à China, às ex-colônias portuguesas e ao Oriente Médio.

A suposta causalidade entre a retórica governamental da diversificação de exportações e as políticas adotadas poderia ser observada, em tese, tanto na decisão de estabelecer relações diplomáticas com a República Popular da China como na decisão de reconhecer as ex-colônias portuguesas. Mas qual foi o impacto do cálculo da potencialidade desses mercados para os produtos brasileiros nas decisões governamentais mencionadas?

No caso do relacionamento do Brasil com a China, antes do governo Geisel, havia um componente comercial na maior interação entre os dois países. Foi por intermédio de missões empresariais que os primeiros contatos políticos se estabeleceram (Pinheiro 1993, 253-54 e 259). As fontes primárias disponíveis indicam, no entanto, que a explicação do reconhecimento da China estava no

30 Uma voz contrária relevante era a do ministro da Agricultura, Alysson Paunielli, sobre a agenda agrícola do Sela. G.M. no 744. De Alysson Paunielli para Antônio Francisco Azeredo da Silveira. 24 de dezembro de 1976. 
desejo de o Brasil ter uma política externa independente, colocando em prática o elemento "ecumênico" do pragmatismo responsável e projetando seus interesses de maneira condizente com seu novo status internacional. ${ }^{31}$ Nesse caso, portanto, a relação entre a justificativa econômica e as reais motivações do governo brasileiro destoa de forma nítida.

A retórica sobre os ganhos econômicos serviu, primariamente, para o esforço de justificação da decisão de reatamento, que era eminentemente política. ${ }^{32}$ Isso não significava a inexistência de interesse em aumentar o intercâmbio comercial. Muito pelo contrário - em conversas privadas com terceiros sempre se salientava essa motivação, assim como no diálogo entre os dois governos antes do reconhecimento. Mas o potencial comercial da relação não explica a ação brasileira. ${ }^{33} \mathrm{~A}$ distância entre a retórica e o elemento causal pode ser vista na discrepância dos interesses existentes na sociedade e no governo, e o reconhecimento da escassa potencialidade do comércio bilateral. ${ }^{34}$ Com efeito, o comércio entre o Brasil e a China era muito limitado: o Brasil havia exportado US\$ 70 milhões em 1972 e US\$ 65 milhões em 1973, principalmente açúcar e algodão. Por sua vez, as importações provenientes da China eram quase inexistentes. A visita da missão comercial chinesa ao Brasil, em agosto de 1974, que buscava incrementar os laços comerciais entre os dois países, serviria, assim, para dar credibilidade à justificativa econômica do reatamento, apesar de a única medida concreta na reunião bilateral ter sido um contrato de fornecimento de açúcar para a China. Os próprios empresários paulistas participantes do processo indicavam que não viam nenhum desenvolvimento significativo dos prospectos comerciais chineses, nem mesmo em médio e em longo prazo. O embaixador americano no Brasil comentaria, após o encontro, que os aspectos econômicos da visita ficaram somente no nível das expressões retóricas. ${ }^{35}$

Se a retórica econômica servia, primordialmente, para justificar o reatamento, o que explicaria, além das razões já citadas, a própria decisão? Considerando a ação externa como uma sinalização aos atores domésticos, poder-se-ia argumentar que

31 "Na medida (...) em que se consolida a presença do Brasil no cenário das naçôes, ampliam-se os seus interesses e, ao mesmo tempo, aumentam suas responsabilidades de potência em ascensão. E é nesse contexto que se insere, ao se formular a política exterior brasileira, a questão das relaçōes do Brasil com a República Popular da China." Exposição de Motivos do Ministério das Relaçôes Exteriores. G/110/920 (B46) (E33). 9 de abril de 1974. Secreto. EG pr 1974.03.00/2.

32 SEPLAN. O desenvolvimento econômico na República Popular da China e as perspectivas de Comércio. EG pr 1974.03.00/2; Conselho de Segurança Nacional. Estudo sucinto no 053/1 a SC/74. 17 de julho de 1974. Secreto. EG pr 1974.03.00/2; NARA. De John Crimmins (Brasília) para o State Department. Brazilian-Chinese relations. 3 de setembro de 1974 . Confidencial.

33 "Trata-se, a China Comunista, de um mercado mais potencial do que atual, complexo e, no momento, com pequena expressão no contexto internacional." Reconhecimento e estabelecimento de relações diplomáticas com a República Popular da China (RPC). Estudo Sucinto no 053/1a.SC/74. 17 de julho de 1974. Secreto. EG 1974.03/2 pr. Pasta II.

34 De acordo com Azeredo da Silveira, buscava-se "(...) enfatizar a questão econômica apenas para tornar palatável o reconhecimento. Mas o problema era exclusivamente político. O econômico viria com o tempo. (...) a intenção era política" (apud Pinheiro 1993, 60).

35 NARA. De John Crimmins (Brasília) para o State Department. PRC mission to Brazil - trade aspects. 20 de setembro de 1974. 
a tomada de posição brasileira pode ser entendida dentro da lógica governamental de abertura política. Equilibrando-se entre a emergência da pressão para a abertura política e a obstinação da linha dura, Geisel poderia ter utilizado o reatamento com a China como sinalização de sua autoridade aos grupos militares que desejavam prosseguir com a implementação do confronto contra as oposições ao regime. $\mathrm{O}$ presente estudo não apresenta evidências que sustentem essa interpretação, mas propõe pesquisa futura que busque dirimir a questão. O importante, para os fins deste trabalho, é que as evidências disponíveis eliminam a hipótese de que a decisão de reatamento com a China foi uma instância do projeto de diversificação de exportações do governo Geisel.

Outro domínio de discussão na literatura diz respeito a como o reconhecimento das ex-províncias ultramarinas portuguesas foi afetado por razões de diversificação de exportaçôes. Em uma conversa com o embaixador americano no Brasil, o chefe do Departamento de África do Itamaraty, Ítalo Zappa, afirmava que a diplomacia brasileira não possuía nenhum "esquema econômico grandiloquente" para a região. A decisão brasileira de reconhecer Guiné-Bissau, por exemplo, era uma forma de desvincular o País de um modelo antiquado de antagonismo nas relações do País com a África e não se baseava na potencialidade de ganhos econômicos. O País, portanto, movia-se com interesses estritamente políticos. Era uma decisão calcada na consolidação dos laços africanos em um novo enquadramento da política externa. ${ }^{36} \mathrm{O}$ caso de Moçambique também foi adverso para a realização de aumento dos fluxos comerciais, dado os ressentimentos existentes contra o apoio brasileiro aos portugueses (Penna Filho e Lessa 2007).

O caso angolano, por sua vez, era mais complicado. Havia claro desejo do governo brasileiro em abrir novos mercados para produtos industrializados e conseguir fornecimento de petróleo. No entanto, a implementação desses laços comerciais com o país africano não veio da forma como se esperava (Gaspari 2004, 126; Pinheiro 2007, 84). Assim como no caso chinês, Angola era bastante sensível domesticamente, por Luanda estar sob claras tendências comunistas após a vitória do Movimento Popular de Libertação de Angola (MPLA). Por conta dessa situação, buscou-se um perfil baixo para o relacionamento com o país após o reconhecimento de sua independência (Pinheiro 2007, 105).

Isso demonstra que, entre intençôes e comportamento, há diversas variáveis intervenientes que limitam a capacidade dos decisores de atingir seus objetivos. Enquanto Angola apresentava grande demanda por remédios, alimentos e equipamentos, oferecendo-se para pagar adiantadamente à vista e em dólares, o Brasil não se dispôs a apoiar as transações no ritmo que se esperava (Melo 2000, 123). Mais uma vez, a política doméstica obstou a realização dos interesses de diversificação de parcerias da gestão Geisel.

36 NARA. Da embaixada americana em Brasília para o State Department. Guinea-Bissau: Ivoraian request for Brazilian good offices. 24 de novembro de 1973. Confidencial; NARA. De John Crimmins (Brasília) para o State Department. Brazilian recognition of Guinea-Bissau. 29 de julho de 1974. Confidencial. 
Observando-se a forma como a literatura apresenta o desenvolvimento das exportações brasileiras na gestão Geisel, percebe-se que, geralmente, são utilizados dados absolutos ou de distribuição das exportações por destino como indicadores do sucesso de uma política de diversificação de exportaçōes. A dificuldade, no entanto, é que esses dados não são suficientes para indicar o vínculo de causalidade proposto. Na década de 1970, várias economias periféricas cresciam a ritmo superior aos países centrais - o que justificaria o crescimento da participação desses países na pauta de exportação brasileira.

Para avaliar os reais efeitos de uma política de diversificação de exportações, podemos utilizar dois tipos de estudos: um quantitativo e outro documental. O quantitativo busca examinar a participação brasileira na distribuição das importações de outros países e regióes, o que indicaria, em termos comparados, se o País aumentou ou reduziu sua participação nesses mercados. O estudo documental demonstraria até que ponto o esforço de promoção comercial do País na gestão Geisel foi uma resposta a uma demanda do próprio crescimento das economias periféricas.

Analisando os dados, chega-se a relevante conclusão: o avanço do País em mercados não tradicionais (países em desenvolvimento e exportadores de petróleo) durante a gestão Geisel, em termos comparados, teve resultados pífios. Com efeito, a maior expansão relativa do País ocorreu entre 1971 e 1973; antes, portanto, do marco temporal deste estudo.

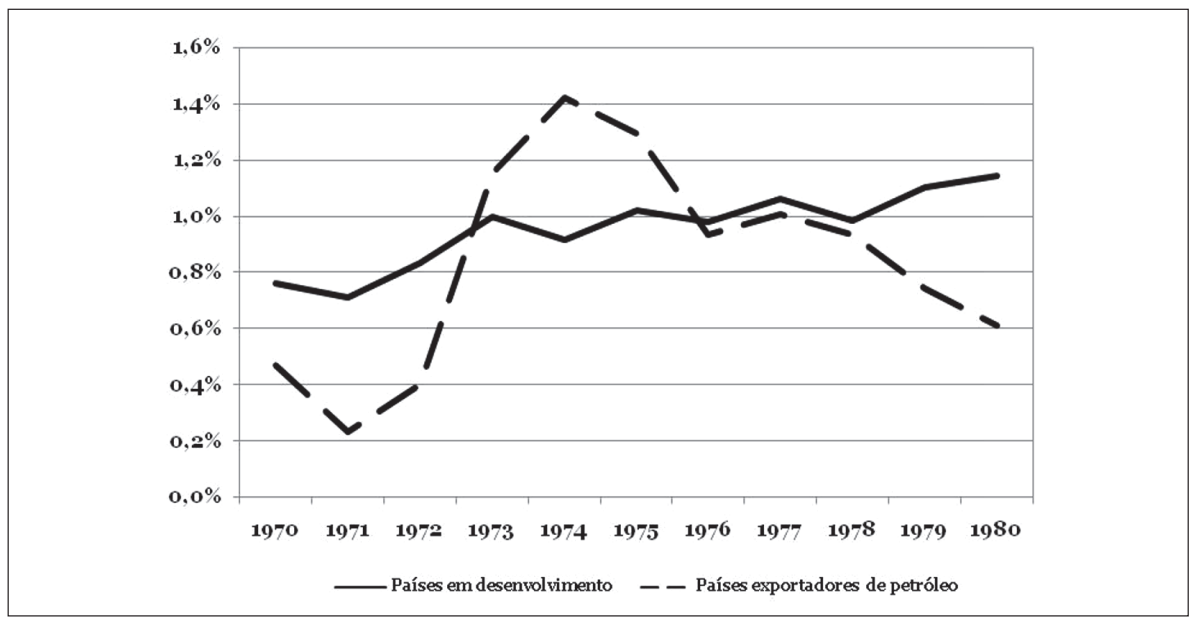

Gráfico 3. Participação do Brasil nas importações globais dos países em desenvolvimento e dos países exportadores de petróleo, 1970-1980.

Fonte: Direction of Trade Statistics/IMF.

Podem-se realizar testes com países específicos utilizando a base de dados comerciais do Fundo Monetário Internacional (FMI). No caso do Iraque, 
os resultados são igualmente interessantes. Primeiro, outros países também aumentaram seu volume de exportações para o país; ou seja, o Brasil não foi caso isolado. Segundo, o Brasil era um dos grandes exportadores para o Iraque, entre os países em desenvolvimento, chegando a responder por até $20 \%$ das exportações desse grupo de países para o Iraque. Porém, se observarmos os dados na perspectiva das importações globais iraquianas, vemos um pico da participação brasileira em 1973 - antes que os efeitos do choque do petróleo fossem sentidos. Nos anos seguintes, a participação cai gradualmente até chegar em 1,1\%, em $1978 .{ }^{37}$ Confirma-se, portanto, nesse caso específico, a hipótese de que o Brasil não expandiu e diversificou-se de forma tão acentuada no período, se comparado com outros países.

$\mathrm{Na}$ disputa mundial por novos mercados após o choque do petróleo, não se pode dizer que o Brasil foi bem-sucedido. Isso não quer dizer que o País não aumentou as vendas para esses países. As exportaçóes para países em desenvolvimento não exportadores de petróleo passaram de US \$ 1,3 bilhão em 1974 para US \$ 3,7 bilhōes em 1979, e as exportações para os países exportadores de petróleo subiram de US\$ 460 milhões para US\$ 670 milhões no mesmo período. Mas essas cifras não indicam se o aumento decorreu de esforços de promoção comercial.

De fato, no auge da crise do petróleo, seria de se esperar que os exportadores de petróleo aumentassem suas importaçôes, o que se refletiu no crescimento dos números absolutos de importação originada no Brasil. No entanto, em termos da participação relativa brasileira nesses mercados, não se observaram melhoras significativas. $\mathrm{O}$ aumento dos fluxos comerciais bilaterais apenas reflete o fato de que os países exportadores de petróleo viram sua renda aumentar substantivamente no período.

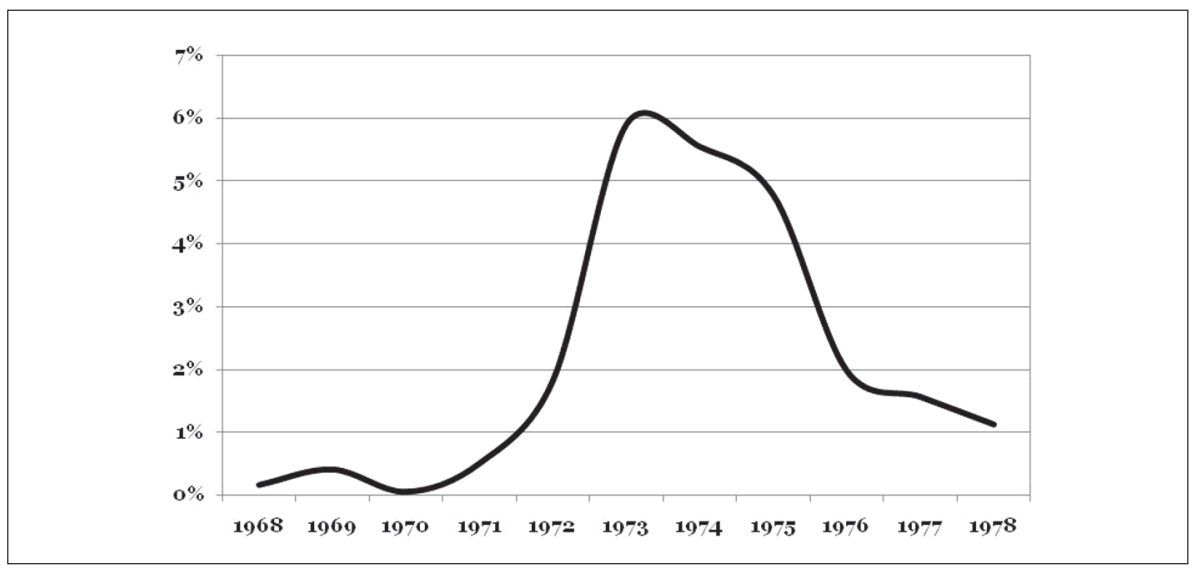

Gráfico 4. Participação do Brasil nas importações globais do Iraque, 1968-1980. Fonte: Direction of Trade Statistics/IMF.

37 Em decorrência da guerra Irã-Iraque, não há dados para o período posterior a 1978. 
Identifica-se, além disso, a partir dos Gráficos 5 e 6, uma tendência de longo prazo - iniciada nos anos 1950 - de diminuição da participação de parceiros tradicionais (Estados Unidos e Europa Ocidental) no comércio exterior brasileiro e de aumento da participação do grupo de países em desenvolvimento. Os dados disponíveis indicam, portanto, que o processo de diversificação das parcerias comerciais do País possui uma longa trajetória anterior e não constitui característica distintiva da inserção econômica internacional do governo Geisel.

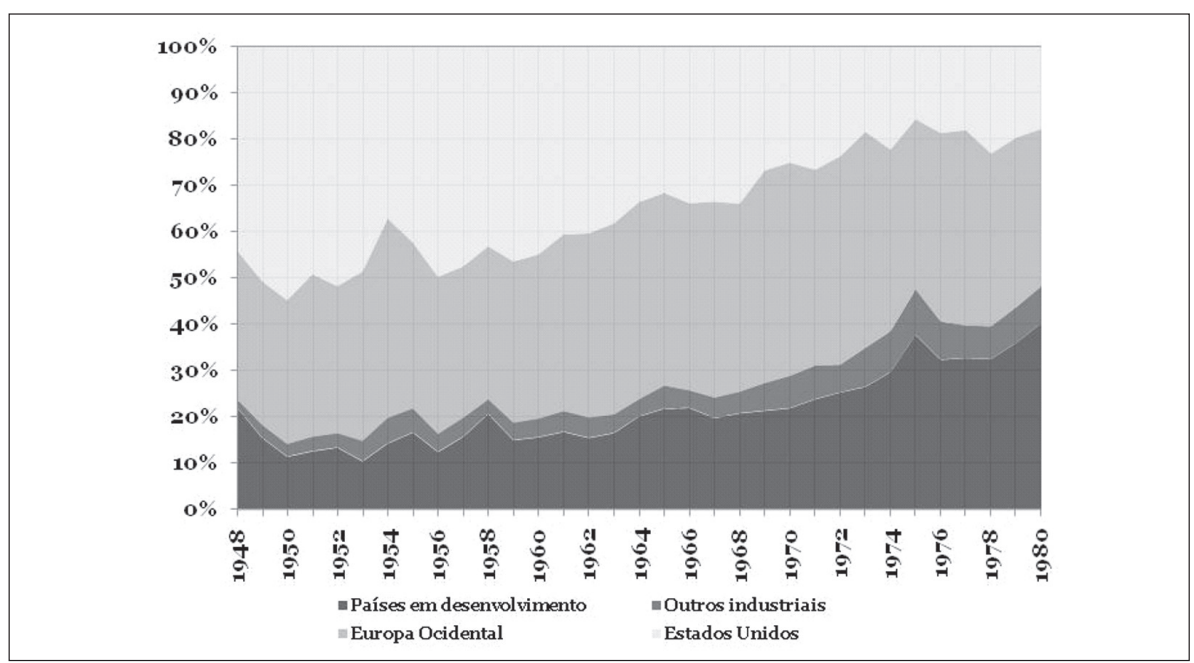

Gráfico 5. Exportações brasileiras por país de destino, 1948-1980.

Fonte: Direction of Trade Statistics/IMF.

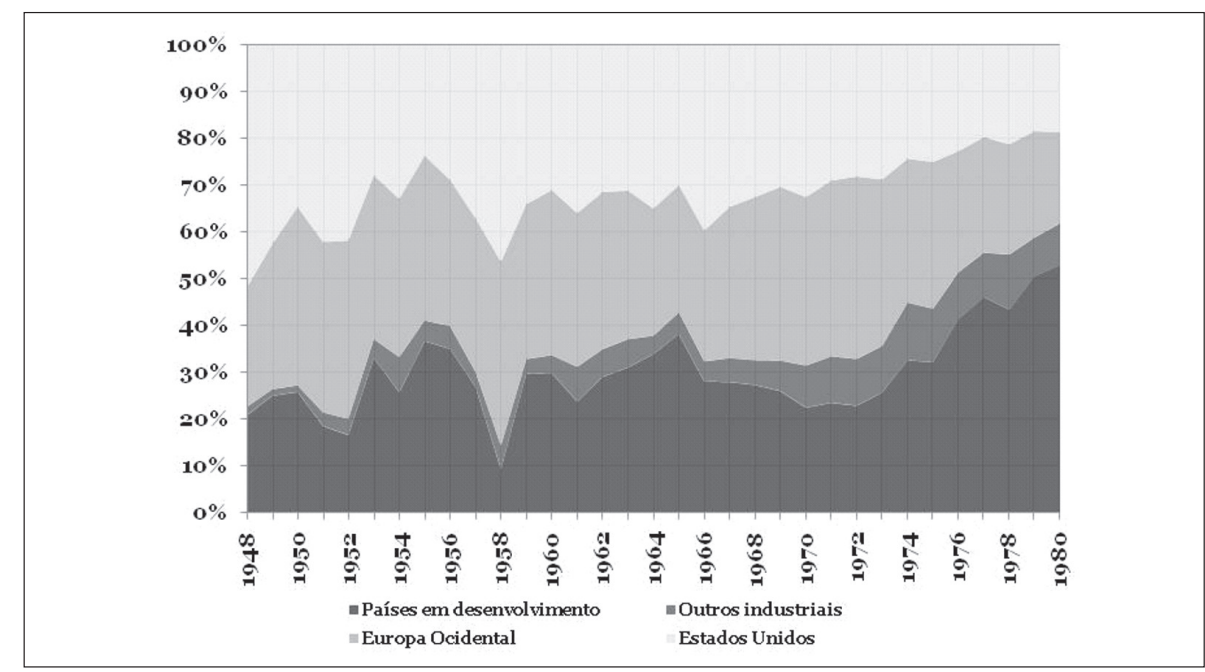

Gráfico 6. Importações brasileiras por país de origem, 1948-1980.

Fonte: Direction of Trade Statistics/IMF. 
Do ponto de vista documental, as evidências disponíveis confirmam o argumento aqui apresentado: a súbita demanda externa por importaçôes teve grande importância no aumento das exportações brasileiras para destinos não tradicionais. A criação da Interbrás, em 1976, foi sintomática. Ao final de 1974, Ueki relata a Geisel que a Petrobras estava sendo continuamente solicitada para intermediar negócios de exportação em países em que tinha presença, sem, no entanto, conseguir atender aos pedidos de forma sistemática. Germinava, então, a ideia de que a empresa poderia ser grande exportadora de produtos brasileiros. Os dois decisores, no entanto, não desejavam expandir ainda mais o sistema de promoção comercial vigente à época. Eles concordavam que a Braspetro, empresa responsável pela exploração e produção de petróleo no exterior, deveria auxiliar os exportadores brasileiros, mas era inconveniente a criação de uma trading, pois a Petrobras possuía importantes missões no exterior ainda não cumpridas.

A elevada demanda dos países exportadores de petróleo por produtos brasileiros - sobretudo Iraque, Argélia e Líbia -, por sua vez, sinalizava a vários participantes do sistema de promoção comercial do País que a posição de Geisel era equivocada. Eles se mobilizaram, e, em meados de 1975, a elevada expansão das atividades comerciais da Braspetro e a pressão junto ao governo levaram Geisel e Ueki a recuar e aceitar a criação da Interbrás, em novembro de $1975 .{ }^{38}$ Foi, portanto, a demanda dos importadores por produtos brasileiros e a iniciativa de funcionários do sistema de promoção comercial que levaram o governo a criar o que viria a ser a principal iniciativa institucional de expansão do comércio exterior da década de 1970 .

\section{Conclusão}

Este estudo buscou apresentar um esquema analítico que ajude a explicar o comportamento do Brasil na economia política internacional. Não se pretendeu formular um modelo explicativo acabado, mas um mapa que indique onde encontrar as variáveis explicativas relevantes e a direção dos fluxos de causalidade entre elas. A variável dependente é a política externa econômica brasileira. A variável independente é a posição relativa do País na estrutura de distribuição internacional de poder econômico - uma variável de nível sistêmico. Há, ademais, um conjunto de variáveis intervenientes relevantes, localizadas no nível doméstico. As principais identificadas pela literatura, e reiteradas neste estudo, são: ideias e percepçõos dos tomadores de decisão; clivagens interburocráticas; e fatores relacionados às dinâmicas da política doméstica.

Como ressaltado, trata-se de estudo inicial que visa a mapear o conjunto de variáveis relevantes para se entender a inserção econômica internacional do Brasil.

$3825^{\circ}, 43^{\circ}$ e $47^{\circ}$ despachos com o ministro das Minas e Energia (19/12/74). EG pr 1974.03.26/2. 
Partimos de estudos de casos restritos à gestão Geisel, mas acreditamos que o esquema proposto possui alcance mais amplo: ajuda a explicar a política externa econômica de outros períodos e fornece parâmetros para o estudo comparado com outros países.

\section{Referências bibliográficas}

\section{Fontes primárias}

Acervos Azeredo da Silveira (AAS) e Ernesto Geisel (EG) do CPDOC/FGV

Arquivo do Fundo Monetário Internacional (FMI)

National Archives (NARA)

O Estado de São Paulo

\section{Artigos, livros e teses}

Baer, Werner. A economia brasileira. 2a edição. São Paulo: Nobel, 2002.

Batista, Jorge Chami. A estratégia de ajustamento externo do Segundo Plano Nacional de Desenvolvimento. Revista de Economia Política, v. 7, n. 2, abril-junho de 1987.

Cacho, Joyce Agnes Sabina. Growth in Brazil's soybean processing industry and government policies, 1970-93. (Ph.D.) Columbia (MO): University of Missouri-Columbia, 1999.

Castro, Antonio Barros de e Souza, Francisco Eduardo Pires de. A economia brasileira em marcha forçada. Rio de Janeiro: Paz e Terra, 1985.

Coes, Donald V. Trade, international payments, and Brazil's economic growth. Latin American Research Review, v. 26, n. 2, p.171-86. 1991.

Coes, Donald V. Macroeconomic crises, policies, and growth in Brazil, 1964-90. Washington, D.C.: The World Bank, 1995.

D’Araujo, Maria Celina e Castro, Celso, Eds. Ernesto Geisel. Rio de Janeiro: Editora Fundação Getúlio Vargas. 1997.

D’Araujo, Maria Celina e Castro, Celso. Tempos modernos: João Paulo dos Reis Velloso, memórias do desenvolvimento. Rio de Janeiro: Editora da FGV, 2004.

Devlin, Robert. Debt and crisis in Latin America: the supply side of the story. Princeton (NJ): Princeton University Press, 1989.

Faminow, Merle D. e Hillman, Jimmye S. Embargoes and the emergence of Brazil's soyabean industry. The World Economy, v. 10, n. 3, p.351-66. 1987.

Fishlow, Albert. A economia política do ajustamento brasileiro aos choques do petróleo: uma nota sobre o período 1974/84. Pesquisa e Planejamento Econômico, v. 16, n. 3, p.507-550. 1986.

Frieden, Jeffry A. Debt, development, and democracy: modern political economy and Latin America, 1965-1985. Princeton: Princeton University Press, 1991. 
Friedmann, Harriet. The international political economy of food: a global crisis. In: Counihan, Carole M. Food in the USA: A Reader. New York: Routledge, 2002. p. 325-47.

Gaspari, Elio. A ditadura derrotada. São Paulo: Companhia das Letras, 2003.

Gaspari, Elio. A ditadura encurralada. São Paulo: Companhia das Letras, 2004.

Hermann, Jennifer. Auge e Declínio do Modelo de Crescimento com Endividamento: O II PND e a Crise da Dívida Externa (1974-1984). In: Giambiagi, Fabio et al. Economia Brasileira Contemporânea. Rio de Janeiro: Elsevier, 2005. p. 93-115.

Hopkins, R. F. Food Policymaking. Proceedings of the Academy of Political Science, v. 34, n. 3, p.12-24. 1982.

Iglesias, Roberto Magno; Veiga, Pedro da Motta. "Promoção de Exportaçôes via Internacionalização das Firmas de Capital Brasileiro". In: Pinheiro, Armando C.; Markwald, Ricardo; Pereira, Lia Valls. O Desafio das Exportaçôes. Rio de Janeiro: BNDES, 2002.

Lessa, Antônio Carlos. A estratégia de diversificação de parcerias no contexto do Nacionaldesenvolvimentismo (1974-1979). Revista Brasileira de Politica Internacional, v. 38, n. 1, p.24-39. 1995.

Lima, Maria Regina Soares de. The political economy of Brazilian foreign policy: nuclear energy, trade, and Itaipu. (Ph.D.) Nashville: Vanderbilt University, 1986.

Lima, Maria Regina Soares de e Moura, Gerson. A trajetória do pragmatismo: uma análise da política externa brasileira. Dados, v. 25, n. 3, p.349-64. 1982.

Lobell, Steven E., Norrin M. Ripsman, et al. (Eds). Neoclassical realism, the state and foreign policy. Cambridge: Cambridge University Press, 2009.

Macarini, José Pedro. Governo Geisel: transição político-econômica? Um ensaio de revisão. Texto para Discussão. IE/UNICAMP. N. 142, maio 2008. Disponível em: <http://www.eco.unicamp. br/Downloads/Publicacoes/TextosDiscussao/textos142.pdf>. Acesso em: 10 de março de 2009.

Melo, Ovidio de Andrade. O reconhecimento de Angola pelo Brasil em 1975. Comunicação \& Política, v. VII, n. 3, p.75-165. 2000.

Penna Filho, Pio e Lessa, Antônio Carlos Moraes. O Itamaraty e a África: as origens da política africana do Brasil. Estudos Históricos, n. 39, p.57-81. 2007.

Pinheiro, Letícia. Restabelecimento de relações diplomáticas com a República Popular da China: uma análise do processo de tomada de decisão. Estudos Históricos, v. 6, n. 12, p.247-70. 1993.

Pinheiro, Letícia. O reconhecimento da independência de Angola. Estudos Históricos, n. 39, p.83-120. 2007.

Rocha, Angela da, Monteiro, Joana, et al. The emergence of new and successful export activities in Brazil: four case studies from the manufacturing and the agricultural sector. 2007.

Rose, Gideon. Neoclassical realism and theories of foreign policy. World Politics, v. 51, n. 1, p.144-72. 1998.

Schneider, Ronald M. Brazil's foreign policy: a case study in upward mobility. Inter-American Economic Affairs, v. XXVII, n. 4, p.3-28. 1974.

Schweller, Randall L. The progressiveness of neoclassical realism. In: Elman, Colin e Elman, Miriam Fendius. Progress in international relations theory: appraising the field. Cambridge, MA: MIT Press, 2003. p. 311-47. 
Simonsen, Mario Henrique. Brasil 2001. Rio de Janeiro: APEC Editora, 1969.

Singer, Paul. A crise do "Milagre". Rio de Janeiro: Paz e Terra, 1976.

Spektor, Matias. Ruptura e legado: o colapso da cordialidade oficial e a construção da parceria entre o Brasil e a Argentina (1967-1979). (Mestrado). Brasília: Universidade de Brasília, 2002.

Spektor, Matias. Origens e direção do Pragmatismo Ecumênico e Responsável (1974-1979). Revista Brasileira de Politica Internacional, v. 47, n. 2, p.191-222. 2004.

Stepan, Alfred. The military in politics: changing patterns in Brazil. Princeton: Princeton University Press, 1971.

Zakaria, Fareed. From wealth to power: the unusual origins of America's world role. Princeton, N.J.: Princeton University Press, 1998.

Recebido em 12 de janeiro de 2011 Aprovado em 14 de fevereiro de 2011

\title{
Resumo
}

Este artigo propõe quadro analítico para descrever e explicar a economia política das relações econômicas externas brasileiras durante o governo Geisel. Utilizam-se variáveis do sistema internacional, considerando como elas interagem com as ideias e percepções dos tomadores de decisão, as disputas interburocráticas no interior do aparelho do Estado, a política doméstica, e as dinâmicas econômicas exógenas às políticas governamentais.

Palavras-chave: Brasil; economia política internacional; Geisel.

\begin{abstract}
This article proposes an analytical framework to describe and explain the political economy of Brazilian foreign economic relations in the Geisel administration. We use variables from the international system, considering how they interact with decision makers' ideas and perceptions, interbureaucratic disputes within the State apparatus, the domestic politics, and exogenous economic dynamics.
\end{abstract}

Keywords: Brazil; international political economy; Geisel. 